\title{
Research on Asparagus Quality Improvement by Optimum Blanching Medium of Asparagus
}

\author{
Meng xiangren ${ }^{1,}$, , Wang hengpeng ${ }^{2}$ \\ ${ }^{1,2}$ School of Tourism and Culinary Science, Yangzhou University, Yangzhou 225127, Jiangsu, \\ China \\ a445609455@qq.com
}

Keywords: Asparagus; Blanching Medium; Process Optimization

Abstract. Experiment with fresh green asparagus as raw material, Research on three kinds of common blanching medium as water, oil and water mixed oil. Respectively, the antioxidant activity, dry matter dissolution rate and sensory properties of asparagus as an indicator.And the conditions of Blanching medium were optimized by orthogonal experiment based on single factor tests. Results showed that Water mixed oil was the best blanching medium of asparagus, And the optimum conditions for blanching asparagus were: Water-oil ratio 12:1, the ratio of asparagus and media 1 to 3 , At $100^{\circ} \mathrm{C}$ hot system boiling $2 \mathrm{~min}$.In this condition, the antioxidant activity of asparagus was highest,the color was best, and better eating quality was also achieved, dissolution rate of dry matter from blanching asparagus was $1.28 \%$. The blanching asparagus by Water mixed oil could be cooked for various dishes.

\section{Introduction}

Green asparagus, also known as A. officinalis., belonging to the Liliaceae perennial herbaceous perennial plant, plant type appearance, is one of the world's top ten dishes, in the market enjoy the reputation of the "king of vegetables". ${ }^{[1]}$

Asparagus has high nutritional value, a variety of containing nutrition which the human body needs , The nutrients of rutin,saponins of asparagus.etc which unfound in other vegetables. ${ }^{[2]}$ In addition, asparagus can also reduce the content of lipid peroxide in human organs, and then increase the activity of superoxide dismutase, so as to effectively remove the free radicals in the body, delaying senescence. ${ }^{[3]}$

Cooking processing to play a unique color, aroma, taste to induce people's appetite, first of all, it is necessary to carry out the necessary blanching treatment. Common blanching treatment methods include hot water treatment, hot air blanching transfer, hot steam and microwave treatment, etc., which is the most simple and practical hot water temperature in the cooking process. Because of the research on the influence of blanching medium on the quality of asparagus, this paper makes a comparison between water, oil, water and oil in three kinds of blanching media.

\section{Materials and Methods}

\subsection{Materials and Equipment}

\subsubsection{Materials}

Green asparagus: purchased from Yangzhou Metro supermarket, excellent quality;Edible oil: golden dragon fish oil 1.8L.

\subsubsection{Instrument and Equipment}

BS210S(1/1000) Electronic balance, Beijing Saiduosi Instrument System Co. 1td.;101-1-BS Electric blanchinging constant temperature air blast drying box, Shanghai advanced medical instrument factory products;GTR 16-2 High speed refrigerated centrifuge, Beijing era North Lee centrifuge Co.ltd.;721 type spectrophotometer, Shanghai third analysis instrument factory;SB-5200DT ultrasonic cleaning agent, Ningbo Xinzhi biological Polytron Technologies Inc.

\subsubsection{Main Reagent}

95\% ethanol, Changshou City Yang Garden Chemical Co.Ltd.; DPPH analysis of pure, the United States Sigma company 


\subsection{Method}

\subsection{1 blanching Process of Asparagus}

Technological process:Fresh section $\rightarrow$ blanching $\rightarrow$ cooling $\rightarrow$ standby.

asparagus $\rightarrow$ cleaning $\rightarrow$ pruning $\rightarrow$ taking $\quad$ bud

Clean fresh asparagus, remove non edible parts, cut to specifications is $4 \mathrm{~mm} \times 4 \mathrm{~mm} \times 50 \mathrm{~mm}$ neat buds, respectively in water, oil, water and oil mixed in the three different media for blanching treatment, remove is rapidly cooling in ice water, take samples of the same quality were measured the antioxidant activity, dry matter dissolution rate, color and sensory properties.

\subsubsection{Determination of Antioxidant Activity}

\subsubsection{Preparation of DPPH Ethanol Solution}

Weighing DPPH 20mg,add ethanol dissolved and constant volume in $250 \mathrm{ml}$ volumetric flask,DPPH concentration is $2 \times 10^{-4} \mathrm{~mol} / \mathrm{L}$,protected from light at $0 \sim 4^{\circ} \mathrm{C}$ and to use it right after it was ready,valid for $4 \mathrm{~h}$.

\subsubsection{The Preparation of Sample}

Weighing the sample $1.0 \mathrm{~g}$ in test tube, adding $75 \%$ methanol $10 \mathrm{~mL}$,get the supernatant wnich after ultrasonic extraction of $30 \mathrm{~min}, 12000 \mathrm{r} / \mathrm{min} 5 \mathrm{~min}$ to be measured.

\subsubsection{Measurement Steps}

$1.0 \mathrm{ml}$ sample solution mixed with $1.0 \mathrm{ml} 2 \times 10^{-4} \mathrm{~mol} / 1 \mathrm{DPPH}$ solution (A1 tube);1.0ml absolute ethyl alcohol mixed with $1.0 \mathrm{ml} 2 \times 10^{-4} \mathrm{~mol} / 1 \mathrm{DPPH}$ solution (A2tube);1.0ml absolute ethyl alcohol mixed with sample solution(A3tube);after $30 \mathrm{~min}$, use ultraviolet spectrophotometer at $517 \mathrm{~nm}$ wavelength measurement under A1, A2, A3 absorbance values.

Clearance calculation formula is: clearance rate $=[(\mathrm{A} 2+\mathrm{A} 3)-\mathrm{A} 1] / \mathrm{A} 2 \times 100 \%$

\subsubsection{Determination of dissolution rate of dry matter}

Take $50 \mathrm{~g}$ asparagus, according to the optimum formula for processing, calculate the dissolution rate of dry matter in the process of asparagus processing.dissolution rate of dry matter $(\%)=(\mathrm{m} 1-$ $\mathrm{m} 2) / \mathrm{m} \times 100 \%$.Among them, the $\mathrm{m} 1$ mean after drying to the quality of the volumetric flask, $\mathrm{g} ; \mathrm{m} 2$ mean the quality of the volumetric flask;m mean the quality of the former blanch asparagus, $\mathrm{g}$.

\subsubsection{Sensory Evaluation}

Select ten assessors to set up a panel,the sensory quality of asparagus was evaluated according to the principles of food sensory evaluation.Before the experiment, the assessors were trained strictly to make clear the sensory index of asparagus.Evaluation environment simulating normal consumption environment, no smell, no noise, tasting staff access to convenient and preparation area have obvious interval, and is not affected by the influence of sample preparation area smell.Room temperature is $21{ }^{\circ} \mathrm{C} \sim 25^{\circ} \mathrm{C}$, relative humidity $55 \% \sim 65 \%$ with good ventilation, assessors don't exchange of opinions, each taste ten people to participate, comment on three times, each with a cup of warm water and paper towels.Comment code is from the computer random three digit encoding, samples using a circular display.For each sample there is comprehensive score of color, hardness,odor, Fracturability.Color, hardness, odor and Fracturability are compared, and two elected think more important one, 100 points method is used to assess, after discussion, colour is accounted for $35 \%$, $25 \%$, the smell of $20 \%$, the Fracturability of $20 \%$.Reference table 1 .

Table 1 Sensory evaluation criteria of green asparagus

\begin{tabular}{ccc}
\hline item & score & evaluation criteria \\
\hline colour & 35 & green, shiny $20 \sim 35 ;$ bright in colour $10 \sim 20 ;$ normal $0 \sim 10$ \\
Hardness & 25 & Firm $15 \sim 25 ;$ soft or hard $0 \sim 15$ \\
Odour & 20 & Aroma of asparagus $10 \sim 20 ;$ Weak Aroma $0 \sim 10$ \\
Fracturability & 20 & Crispy $10 \sim 20 ;$ other $0 \sim 10$ \\
\hline
\end{tabular}

\subsubsection{Selection blanching medium of Asparagus}

Three kinds of common blanching medium as water, oil and water mixed oil(1:10), in temperature $100{ }^{\circ} \mathrm{C}$, and solid-liquid ratio $1: 4$, under the condition of the water for $2 \mathrm{~min}$, sensory evaluation. 


\subsubsection{Single Factor Experiment}

\subsubsection{The effects of Water oil ratio on the quality of asparagus}

Respectively choose water oil ratio of $6: 1,8: 1,10: 1,12: 1,14: 1$, at $100{ }^{\circ} \mathrm{C}$, and solid-liquid ratio $1: 4$ $(\mathrm{g} / \mathrm{mL})$ sustain $2 \mathrm{~min}$,determination of antioxidant activity of asparagus, dissolution rate of dry matter and sensory properties to examine water-oil ratio on the quality of asparagus.

\subsubsection{The effects of liquid ratio on quality of Asparagus}

Choose water oil ratio of 10:1 as medium,respectively choosesolid-liquid ratio 1:2, 1:3, 1:4, 1:5, 1:6,in temperature $100{ }^{\circ} \mathrm{C}$.Determination of antioxidant activity of asparagus, dissolution rate of dry matter and sensory properties to examine solid-liquid ratio on the quality of asparagus.

\subsubsection{The effects of Temperature of Asparagus}

Choose water oil ratio of $10: 1$ as medium and solid-liquid ratio $1: 4(\mathrm{~g} / \mathrm{mL})$, at the temperature of $80^{\circ} \mathrm{C}$, $85^{\circ} \mathrm{C}, 90^{\circ} \mathrm{C}, 95^{\circ} \mathrm{C}, 100^{\circ} \mathrm{C}$ sustain $2 \mathrm{~min}$, Determination of antioxidant activity of asparagus, dissolution rate of dry matter and sensory properties to examine temperature on the quality of asparagus.

\subsubsection{The effects of Time of Asparagus}

Choose water oil ratio of $10: 1$ as medium and solid-liquid ratio $1: 4(\mathrm{~g} / \mathrm{mL})$, at the temperature of $100^{\circ} \mathrm{C}$ sustain $1 \mathrm{~min}, 2 \mathrm{~min}, 3 \mathrm{~min}, 4 \mathrm{~min}, 5 \mathrm{~min}$, Determination of antioxidant activity of asparagus, dissolution rate of dry matter and sensory properties to examine temperature on the quality of asparagus.

\subsubsection{The optimum methodology by orthogonal experiment design.}

In this experiment, the design and analysis of orthogonal test method, based on the single factor experiments, the selection of water-oil ratio, solid-liquid ratio, Blanching temperature and time of four factors, 4 factor 3 level experiment,with asparagus antioxidant activity as the main index, and selection of orthogonal table L9 (34) orthogonal analysis.Four factors, respectively, with A, B, C, D, said with 1,2,3 respectively represent the level of the variable. Orthogonal experimental design factor levels are shown in table 2.

Table 2. Orthogonal factors level table

\begin{tabular}{ccccc}
\hline level & $\begin{array}{c}(\mathrm{A}) \\
\text { water-oil } \\
\text { ratio/mL:mL }\end{array}$ & $\begin{array}{c}(\mathrm{B}) \\
\text { solid-liquid } \\
\text { ratio/g:mL }\end{array}$ & $\begin{array}{c}(\mathrm{C}) \\
\text { Temperature } \\
/{ }^{\circ} \mathrm{C}\end{array}$ & $\begin{array}{c}(\mathrm{D}) \\
\text { Time } \\
/ \mathrm{min}\end{array}$ \\
\hline 1 & $\left(\mathrm{~A}_{1}\right) 8: 1$ & $\left(\mathrm{~B}_{1}\right) 1: 3$ & $\left(\mathrm{C}_{1}\right) 90$ & $\left(\mathrm{D}_{1}\right) 2$ \\
2 & $\left(\mathrm{~A}_{2}\right) 10: 1$ & $\left(\mathrm{~B}_{2}\right) 1: 4$ & $\left(\mathrm{C}_{2}\right) 95$ & $\left(\mathrm{D}_{2}\right) 3$ \\
3 & $\left(\mathrm{~A}_{3}\right) 12: 1$ & $\left(\mathrm{~B}_{3}\right) 1: 5$ & $\left(\mathrm{C}_{3}\right) 100$ & $\left(\mathrm{D}_{3}\right) 4$ \\
\hline
\end{tabular}

\subsubsection{Data Processing}

Data is represented by mean \pm standard deviation. The results were analyzed with at-test using SPSS 13.0,significant difference at 0.05 level.

\section{Results and Analysis}

\subsection{Selection blanching medium of Asparagus}

Different blanching media's influence on the sensory quality of asparagus as shown in table 3 .

Table 3 Effects of different blanching media on the sensory quality of Asparagus

\begin{tabular}{|c|c|c|c|c|c|}
\hline $\begin{array}{l}\text { blanching } \\
\text { medium }\end{array}$ & colour & Hardness & Odour & Fracturability & Score \\
\hline water & dark green & hard & $\begin{array}{c}\text { natural green } \\
\text { asparagus flavours }\end{array}$ & $\begin{array}{c}\text { clear and } \\
\text { melodious sound }\end{array}$ & 78 \\
\hline oil & $\begin{array}{c}\text { green } \\
\text { surface }\end{array}$ & soft & $\begin{array}{l}\text { natural green } \\
\text { asparagus flavours }\end{array}$ & poor sound quality & 75 \\
\hline $\begin{array}{c}\text { water } \\
\text { mixed oil }\end{array}$ & viridis & $\begin{array}{c}\text { neither too } \\
\text { hard, nor } \\
\text { too soft }\end{array}$ & $\begin{array}{c}\text { natural green } \\
\text { asparagus flavours }\end{array}$ & $\begin{array}{l}\text { clear and } \\
\text { melodious sound }\end{array}$ & 88 \\
\hline
\end{tabular}


The table 3 shows that the smell of asparagus haven't changed much and also have natural green asparagus flavours in the three different medium.In the water, asparagus darker color, may be in the process of blanching chlorophyll by oxidase catalysis and the loss is bigger.In oil and water mixed oil medium, maintain good green.Add a certain amount of oil in the water would form a layer of oil film, have played an important role in blocking oxygen,causing oxidase can't contact with oxygen,to maximize the preservation of chlorophyll,therefore present a bright green color. Water and oil mixture medium, soft hard moderate and the brittleness is good, may be in the pan oil and water are under the same conditions, when water is heated to more than $100^{\circ} \mathrm{C}$ on the transpiration of vaporization, and the oil is to maintain a high temperature.Asparagus stick full oil by adsorption, adhesion of grease to asparagus is higher than the water temperature of heating, so that you can in a short period of time to speed up the mature green asparagus and softening.And as a result of the water and oil seepage pressure is higher, forcing the asparagus moderate moisture in cells become crunchy.So hot water oil system of asparagus, on the basis of the original hot water method, improves the temperature and osmotic pressure, causing asparagus presents more crunchy, soft texture. Therefore, the choice for the water mixed oil fresh green asparagus blanching medium is most appropriate.

\subsection{Result of Single Factor Experiment}

\subsubsection{Determination of Water-oil ratio}

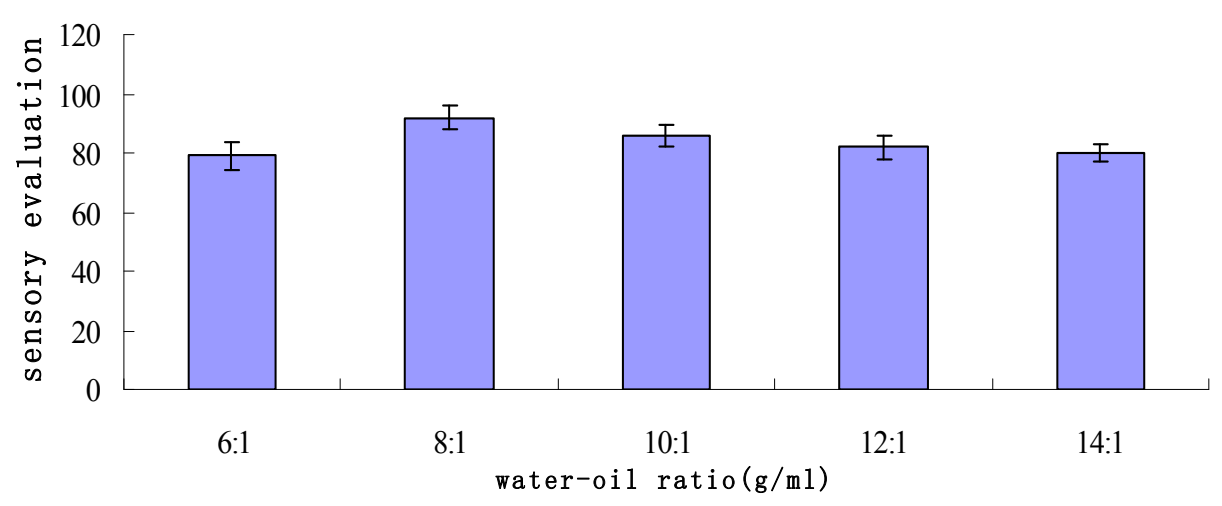

Fig.1 The influence of water-oil ratio on sensory quality of asparagus

The influence of water-oil ratio on sensory quality of asparagus is shown in figure 1. With the increase of water oil ratio, the sensory score of asparagus increased and then decreased.The ratio of water to oil was 6/1, blanching after asparagus showed the surface of the oil slick is more with poor quality.Choose water oil ratio 8/1, 10/1, 10/1 for three levels orthogonal experiment.

\subsubsection{Determination of Solid-liquid ratio}

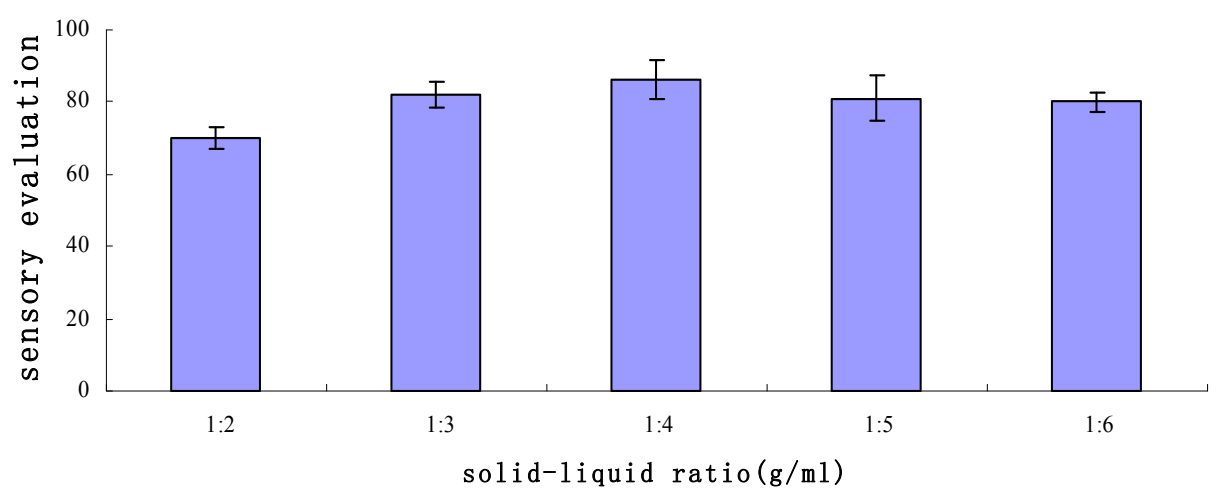

Fig. 2 The influence of solid-liquid ratio on sensory quality of asparagus

Solid-liquid ratio on the sensory quality of asparagus is shown in figure 2 . When the material liquid ratio is $1 / 2$, in the process of the medium evaporation to less, cannot be completely submerged asparagus. Therefore, the selection of $1 / 3,1 / 4,1 / 5$ for the 3 levels of orthogonal experiment. 


\subsubsection{Determination of Temperature}

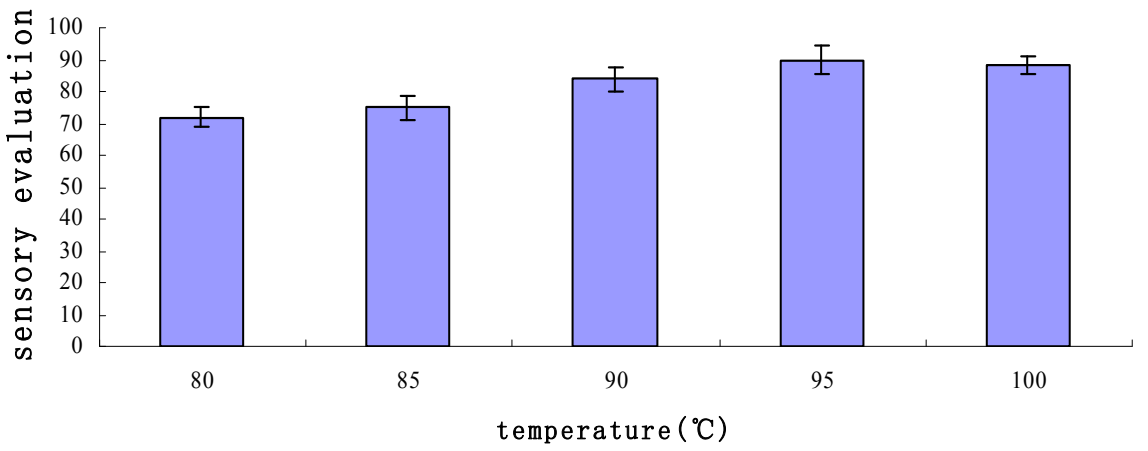

Fig.3 The influence of temperature on sensory quality of asparagus

The effect of the temperature on the sensory quality of asparagus was shown in Figure 3. When the temperature was below 90, the sensory score of asparagus was lower and the color was poor. When the temperature was $95^{\circ} \mathrm{C}$, the sensory quality of asparagus was the best, and the suitable temperature was $90^{\circ} \mathrm{C} \sim 100^{\circ} \mathrm{C}$.

\subsubsection{Determination of Time}

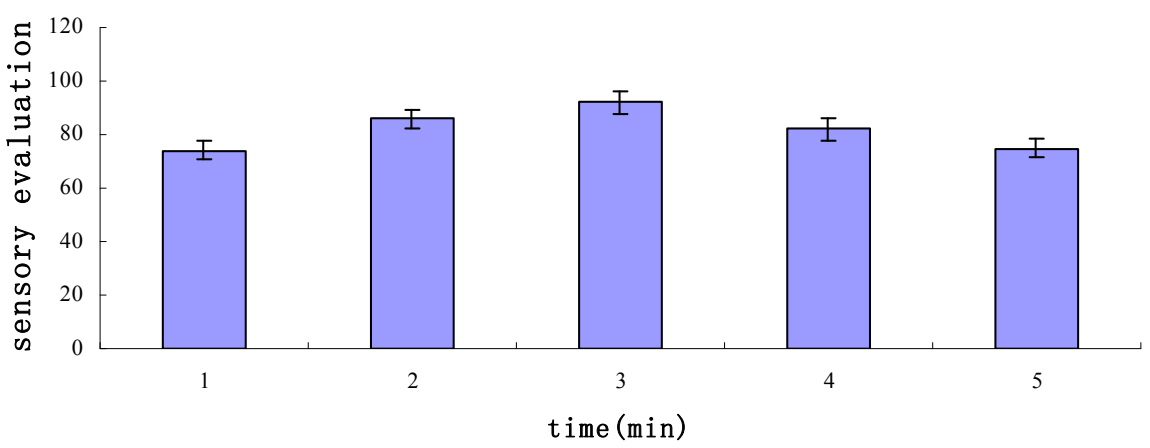

Fig.4 The influence of time on sensory quality of asparagus

The effect of hot time on the sensory quality of asparagus was shown in Figure 4.The time of pressing has a great influence on the sensory quality of asparagus, and the sensory quality of asparagus is the best when the time is $3 \mathrm{~min} .1 \mathrm{~min}$, asparagus hardness larger caused by blanching system time is too short, poor palatability. Asparagus in $5 \mathrm{~min}$ after the performance is too soft, chewing no brittleness. Therefore, the suitable time is $2 \mathrm{~min} \sim 4 \mathrm{~min}$.

\subsection{Result of Qrthogonal Experiment Design}

On the basis of single factor experiment, 3 factors were selected, which were the ratio of water-oil ratio,solid-liquid ratio,the temperature of the heat, and the time of the 4 factors. With asparagus antioxidant activity as the main index, and selection of orthogonal table L9 (34) orthogonal analysis. The results are shown in table 4.

Table 4 Result of Qrthogonal experiment design

\begin{tabular}{cccccc}
\hline number & A & B & C & D & $\begin{array}{c}\text { capacity to scavenge free } \\
\text { radical(\%) }\end{array}$ \\
\hline 1 & 1 & 1 & 1 & 1 & 54 \\
2 & 1 & 2 & 2 & 2 & 60 \\
3 & 1 & 3 & 3 & 3 & 58 \\
4 & 2 & 1 & 2 & 3 & 65 \\
5 & 2 & 2 & 3 & 1 & 73 \\
6 & 2 & 3 & 1 & 2 & 56 \\
7 & 3 & 1 & 3 & 2 & 78 \\
8 & 3 & 2 & 1 & 3 & 55 \\
\hline
\end{tabular}




\begin{tabular}{cccccc}
\hline 9 & 3 & 3 & 2 & 1 & 70 \\
$\mathrm{k}_{1}$ & 57 & 66 & 55 & 66 & \\
$\mathrm{k}_{2}$ & 65 & 63 & 65 & 65 & \\
$\mathrm{k}_{3}$ & 68 & 61 & 70 & 59 & \\
rangeR & 11 & 5 & 15 & 7 & \\
primary and secondary factors & \multicolumn{1}{c}{$\mathrm{C}>\mathrm{A}>\mathrm{D}>\mathrm{B}$} & & \\
optimal combine & $\mathrm{C}_{3} \mathrm{~A}_{3} \mathrm{D}_{1} \mathrm{~B}_{1}$ & & \\
\hline
\end{tabular}

The table 4 shows that the primary and secondary order of factors that influences the quality of asparagus $\mathrm{C}>\mathrm{A}>\mathrm{D}>\mathrm{B}$, namely temperature $>$ water-oil ratio $>$ time $>$ olid-liquid ratio. In the experimental range, the optimum technological conditions of fresh green asparagus were C3A3D1B1, that is, Water-oil ratio 12:1, the ratio of asparagus and media 1 to 3 , At $100^{\circ} \mathrm{C}$ hot system boiling 2 min, under this condition the best quality.

\subsection{Dissolution rate of Dry Matter}

The dry matter dissolution rate of asparagus is the ratio of the quality of the dry matter after blanching and before.The experimental results showed that the dry matter dissolution rate of asparagus was $1.28 \%$, which indicated that the process conditions were favorable for the retention of nutrients of asparagus.

\section{Conclusion}

Experiment with fresh green asparagus as raw material, Research on three kinds of common blanching medium as water, oil and water mixed oil. The results showed that the water mixed oil system of asparagus presents more crunchy, soft texture, water mixed oil for the best medium fresh green asparagus.

Based on the single factor experiment, the orthogonal experiment was carried out to optimize the process conditions of asparagus hot pressing. the optimum conditions for blanching asparagus were: Water-oil ratio $12: 1$, the ratio of asparagus and media 1 to 3 , At $100^{\circ} \mathrm{C}$ hot system boiling $2 \mathrm{~min}$.In this condition, the antioxidant activity of asparagus was highest,the color was best, and better eating quality was also achieved, dissolution rate of dry matter from blanching asparagus was $1.28 \%$. By range analysis results, the main factors affecting the quality of asparagus were as the order of temperature $>$ water-oil ratio $>$ time $>$ solid-liquid ratio .The blanching asparagus by Water mixed oil could be cooked for various dishes.

\section{References}

[1] Kai Sun, Guochen Zhao, Zhe Li. Development of asparagus and utilization prospect in Jilin Province[J]. Agriculture and Technology,2012(5):26-28.In Chinese

[2] Chunyan Sun, Botao Zhao etc. The chemical components and pharmaceutical action of asparagus research progress [J]. Journal of Wild Plant Resources in China,2004(10):16-18.In Chinese

[3] Xuehong Chen. The processing technology of green asparagus juice quality and the effect of antioxidant activity [D]. Nanjing Agricultural University,2012.06.In Chinese

[4] Hunter K J, Fletcher J M. The antioxidant activity and composition of fresh, frozen, jarred and canned vegetables[J].Innovative Food Science and Emerging Technologies, 2002( 3):399-406.

[5] Kexiang Sun. Optimization of Quick-Boiling Technology of Celery[J]. Hubei Agricultural Sciences,2013(3):1401-1403.In Chinese 